\title{
Analisis Dan Perancangan Kebutuhan Sistem E-Learning Berbasis Moodle Pada Program Studi Pendidikan Teknik Informatika Dan Komputer Universitas Negeri Jakarta
}

\author{
M. Ficky Duskarnaen, Dwi Ramadhian, Hamidillah Ajie ${ }^{3}$ \\ 1,2,3 Pendidikan Teknik Informatika dan Komputer Fakultas Teknik \\ Universitas Negeri Jakarta \\ ${ }^{1}$ duskarnaen@unj.ac.id, ${ }^{2}$ dwi_ramadhian@yahoo.com, ${ }^{3}$ hamidillah@unj.ac.id
}

\begin{abstract}
Abstrak
Banyak sekolah maupun perguruan tinggi yang masih menggunakan proses pembelajaran konvensional, yaitu proses belajar mengajar hanya dapat dilakukan ketika terjadi tatap muka antara pengajar dan peserta didik. Hal ini menyebabkan proses pembelajaran terhambat ketika salah satu pihak tidak hadir. Keadaan ini jelas dapat menghambat proses pembelajaran di sekolah maupun pada tingkat perguruan tinggi, yang berakibat kurangnya porsi pembelajaran peserta didik terhadap suatu materi pelajaran. Penelitian ini bertujuan untuk merancang sebuah sistem E-Learning berbasis Moodle agar dapat membantu proses pembelajaran. Penelitian dilakukan di Pusat Teknologi Informasi dan Komputer (PUSTIKOM) UNJ dari bulan Maret sampai bulan Juni 2015. Metode yang digunakan pada penelitian ini adalah Research and Development (R\&D). Setelah melakukan perancangan pada sistem, sistem diuji dengan melakukan simulasi pembelajaran menggunakan fitur-fitur yang telah disediakan oleh Learning Management System (LMS) Moodle, simulasi tersebut dilakukan untuk mengetahui kekuatan dari server maupun dari sisi jaringan komputer yang telah dirancang. Jumlah user saat pengujian disesuaikan dengan jumlah maksimal mahasiswa pada setiap mata kuliah yaitu 40 orang. Dengan uji coba seperti itu maka dapat diketahui kebutuhan maksimal saat sistem E-Learning diakses oleh mahasiswa yang mengikuti kuliah yang ada pada sistem E-Learning.
\end{abstract}

Kata Kunci: sistem E-Learning, E-Learning, Learning Management System (LMS), Moodle.

\section{Pendahuluan}

\section{Latar Belakang}

Seiring dengan pesatnya perkembangan teknologi informasi, konsep dan mekanisme pembelajaran berbasis komputer sudah menjadi suatu kebutuhan yang tidak dapat dipungkiri lagi. Konsep ini dikenal dengan sebutan E-Learning, konsep tersebut membawa pengaruh terjadinya proses transformasi pendidikan konvensional menjadi bentuk digital, baik secara konten maupun sistem.

E-Learning merupakan singkatan dari Electronic Learning, yaitu proses pembelajaran yang memanfaatkan teknologi komputer, jaringan komputer dan Internet dalam proses penyebaran ilmu pengetahuan, sehingga memungkinkan peserta didik untuk belajar melalui komputer saat berada dimana saja tanpa harus secara fisik pergi mengikuti pelajaran/perkuliahan di kelas (Prawiradilaga, 2013: 25).

E-Learning sering pula dipahami sebagai suatu pembelajaran berbasis web yang bisa diakses melalui Internet maupun jaringan lokal. Pada praktiknya, E-Learning memberikan keleluasaan pada peserta didik untuk mengakses materi pembelajaran, dan memudahkan interaksi antara peserta didik dengan pengajar, maupun sesama peserta didik. Peserta didik dapat saling berbagi informasi dan mengakses materi-materi pelajaran setiap saat dan berulang-ulang, dengan demikian perserta didik dapat lebih memantapkan penguasaan terhadap materi pelajaran.

Saat ini konsep E-Learning sudah banyak diterima oleh masyarakat dunia, terbukti dengan maraknya implementasi E-Learning dilembaga pendidikan maupun industri. Selama ini banyak sekolah maupun perguruan tinggi yang masih menggunakan proses pembelajaran yang bersifat konvensional, dengan kata lain proses belajar mengajar antara pendidik dan peserta didik hanya dapat dilakukan dengan syarat terjadinya pertemuan di dalam kelas. Jika pertemuan antara pendidik dan peserta didik tidak terjadi, maka secara otomatis proses pembelajaran tidak dapat dilaksanakan. Proses transfer ilmu pengetahuan pun hampir sepenuhnya dilakukan di dalam kelas, hal ini yang menyebabkan 
terhambat proses pembelajaran jika pertemuan tidak terjadi. Keadaan seperti ini sangat jelas dapat menghambat proses pembelajaran di sekolah maupun pada tingkat perguruan tinggi, yang berakibat kurangnya porsi pembelajaran peserta didik terhadap suatu materi pelajaran.

Disisi lain masih banyak sekolah maupun perguruan tinggi yang belum mempunyai suatu sarana untuk mengelola dan mengembangkan $E$ Learning, khususnya dibidang teknologi informasi dan infrastruktur, sebagai sarana yang digunakan untuk memberikan dan menyebarluaskan materi pembelajaran kepada para peserta didik. Pada Universitas Negeri Jakarta, khususnya Program Studi Pendidikan Teknik Informatika dan Komputer, sampai saat ini belum memiliki format E-Learning, baik dalam infrastruktur maupun sistem teknologi informasi. Maka dari itu perlu dibuat suatu rancangan sistem E-Learning yang nantinya dapat diakses oleh mahasiswa Program Studi Pendidikan Teknik Informatika dan Komputer, dengan akses kapan saja dan dimana saja sehingga dapat mendukung proses pembelajaran serta mempermudah dalam penyebaran ilmu pengetahuan kepada peserta didik.

\section{Dasar Teori}

\subsection{Server}

Sesuai dengan namanya, Server bisa diartikan sebagai pelayan pada suatu jaringan komputer, dengan kata lain Server adalah komputer yang berfungsi untuk melayani, membatasi, dan mengontrol akses terhadap client-client yang terhubung kepadanya dan sebagai pusat sumber daya yang dapat diakses melalui jaringan komputer. Server didukung spesifikasi/kemampuan hardware yang besar (berbeda denga komputer biasa), seperti (Zulhikam, 2015):

1. Ukuran dari memori atau RAM yang cukup besar untuk menampung jumlah query yang dijalankan oleh komputer yang terhubung. Hal ini dikarenakan komuter Server memberikan layanan kepada sejumlah besar komputer maka dibutuhkan memori yang besar untuk mendukung tugas utamanya.

2. Untuk mengelola data, dibutuhkan prosesor dengan kecepatan tinggi, kecepatan prosesor biasanya diukur dalam satuan Giga Hertz, tugas dari prosesor adalah untuk mengolah perintah yang diberikan dari komponenkomponen Server. Sebuah Server harus memiliki prosesor dengan kecepatan tinggi agar dapat bekerja secara optimal, oleh karena itu prosesor yang digunakan harus mampu memberikan fasilitas multitasking.
3. Kapasitas penyimpanan harddisk dari komputer Server haruslah besar, agar dapat menyimpan semua data. Dalam sebuah jaringan komputer, server akan menyimpan data-data dari komputer client.

\subsection{E-Learning}

E-Learning merupakan singkatan dari Electronic Learning, yaitu proses pembelajaran yang memanfaatkan teknologi komputer, jaringan komputer dan Internet dalam proses penyebaran ilmu pengetahuan, sehingga memungkinkan peserta didik untuk belajar melalui komputer saat berada dimana saja tanpa harus secara fisik pergi mengikuti pelajaran/perkuliahan di kelas (Prawiradilaga, 2013: 25)

Jadi dapat disimpulkan bahwa terdapat 2 persepsi tentang pemahaman dari E-Learning itu sendiri, yaitu:

1. Electronic Based Learning adalah pembelajaran yang memanfaatkan teknologi dan komunikasi, terutama yang berupa elektronik. Artinya tidak hanya internet, melaikan semua perangkat elektronik seperti film, video, kaset, OHP, Slide, LCD, projector, dan lain-lain.

2. Internet Based adalah pembelajaran yang digunakan fasilitas Internet yang bersifat online sebagai instrumen utamanya. Maka peserta didik haruslah memiliki fasilitas komputer yang terhubung dengan Internet. Sehingga dalam mengakses materi pembelajaran tidak terbatas oleh jarak, ruang, dan waktu.

\subsection{Moodle}

Definisi Moodle sebagai singkatan dari Modular Object-Oriented Dynamic Learning Environment yang berarti tempat belajar dinamis dengan menggunakan model berorientasi objek. Aplikasi Moodle pertama kali dikembangkan oleh Martin Dougiamas pada Agustus 2002 dengan Moodle versi 1.0 (Cole and Foster, 2008: 7). Selain itu Moodle juga dapat diartikan sebagai kata kerja yang berarti proses melakukan sesuatu seperti permainan yang menyenangkan dan mengarah pada penambahan wawasan dan kreativitas.

Moodle dapat diinstal secara online maupun offline. Sistem yang dibutuhkan agar aplikasi Moodle dapat berjalan dengan baik secara offline adalah Apache Web Server, PHP, database MySQL. Moodle yang diisntal secara online membutuhkan Hosting, domain, dan file Moodle.

\section{Metodologi}

Metode yang digunakan dalam penelitian ini adalah Research and Development. Metode ini 
merupakan metode penelitian yang digunakan untuk menghasilkan produk tertentu dan menguji keefektifan produk tersebut.

Diadaptasi dari Borg dan Gall, Sugiyono merumuskan metode research and development ke dalam 10 langkah (Sugiyono, 2011:298), yaitu:

1. Mengidentifikasi masalah

2. Pengumpulan data

3. Merancangan sistem

4. Validasi rancangan sistem

5. Merevisi rancangan sistem

6. Menguji rancangan sistem pada skala kecil

7. Merevisi rancangan sistem

8. Menguji rancangan sistem pada skala besar

9. Merevisi rancangan sistem

10. Menerapkan rancangan sistem

\section{Hasil dan Analisis}

\subsection{Hasil Penelitian}

Pengujian dilakukan dengan dua cara, yaitu pengujian dengan skala kecil dan pengujian dengan skala besar.

Parameter yang akan diukur pada saat mengujian sistem E-Learning adalah:

1. Kinerja Central Processing Unit (CPU) pada saat keadaan normal atau sebelum sistem E-Learning diakses dan keadaan setelah diakses,

2. Kinerja Disk pada saat keadaan normal atau sebelum sistem E-Learning diakses dan keadaan setelah diakses,

3. Kinerja Network/Jaringan pada saat keadaan normal atau sebelum sistem $E$ Learning diakses dan keadaan setelah diakses,

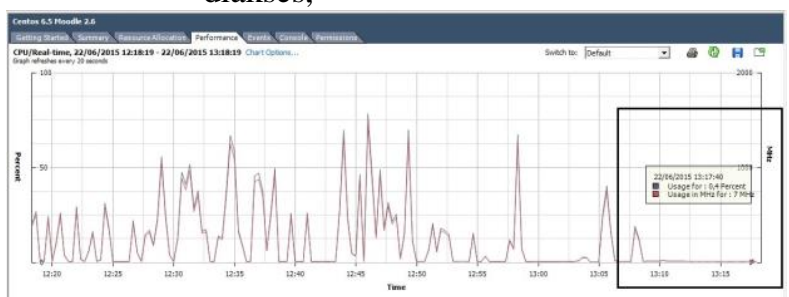

Gambar 1. Grafik CPU saat keadaan normal

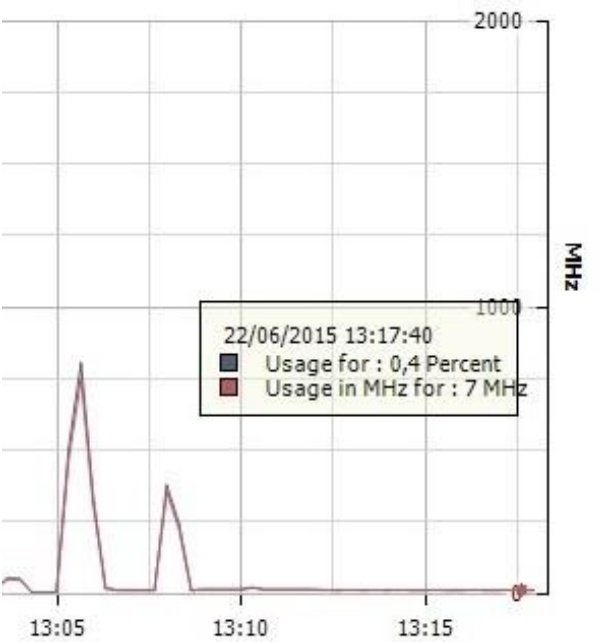

Gambar 2. Grafik CPU saat keadaan normal

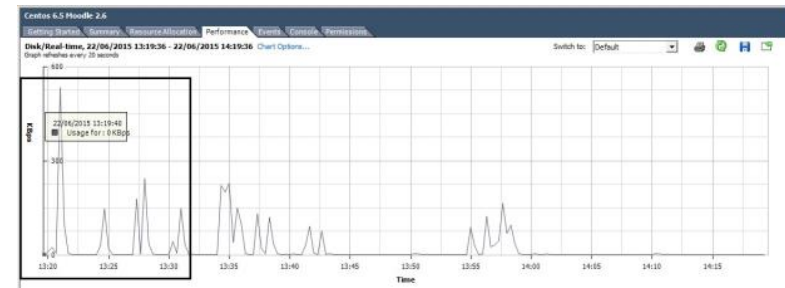

Gambar 3. Grafik Disk saat keadaan normal

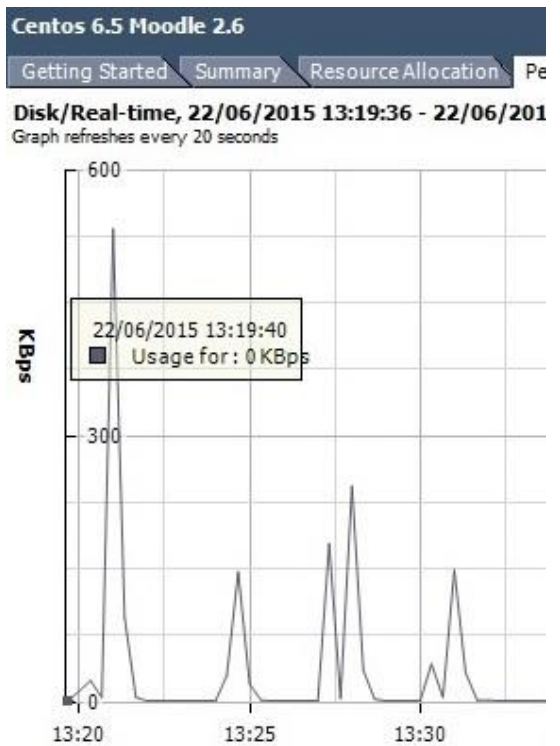

Gambar 4. Grafik Disk saat kedaan normal

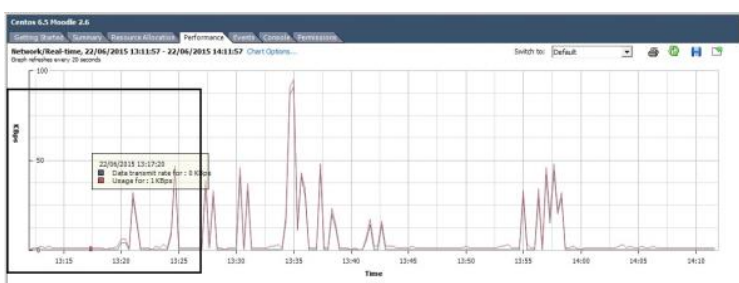

Gambar 5. Grafik Jaringan saat keadaan normal 


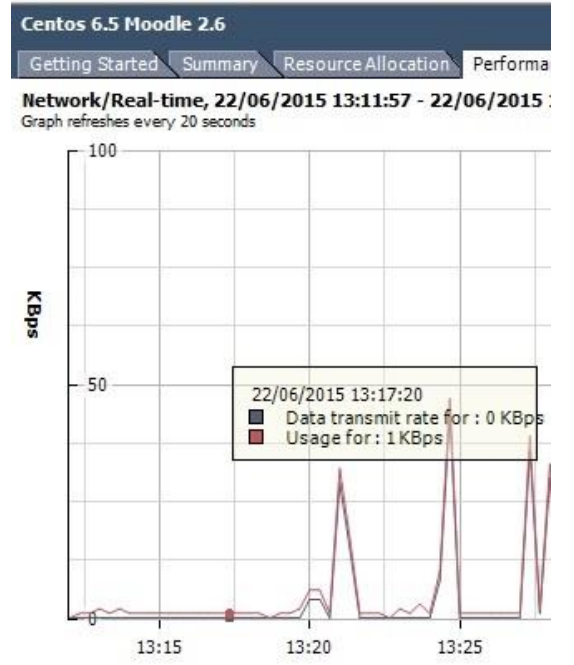

Gambar 6. Grafik Jaringan saat keadaan normal

\subsection{Hasil Pengujian Skala Kecil}

Pengujian skala kecil dilakukan untuk mengetahui apakah perangkat server mengalami beban kerja saat sistem E-Learning tersebut diakses oleh 4 user dan telah berfungsi sebagaimana mestinya atau tidak. Hasilnya adalah semua grafik kinerja telah berjalan sebagaimana mestinya tanpa ada kendala.

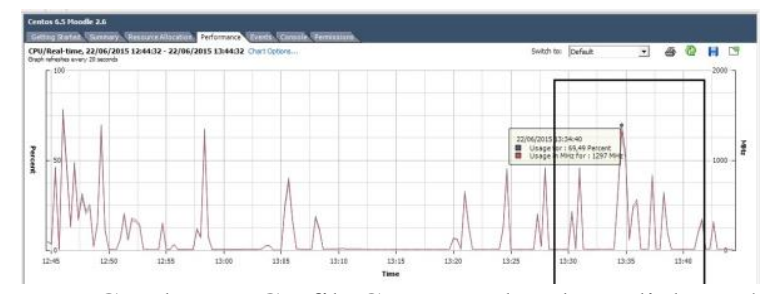

Gambar 7. Grafik CPU saat keadaan diakses 4 user

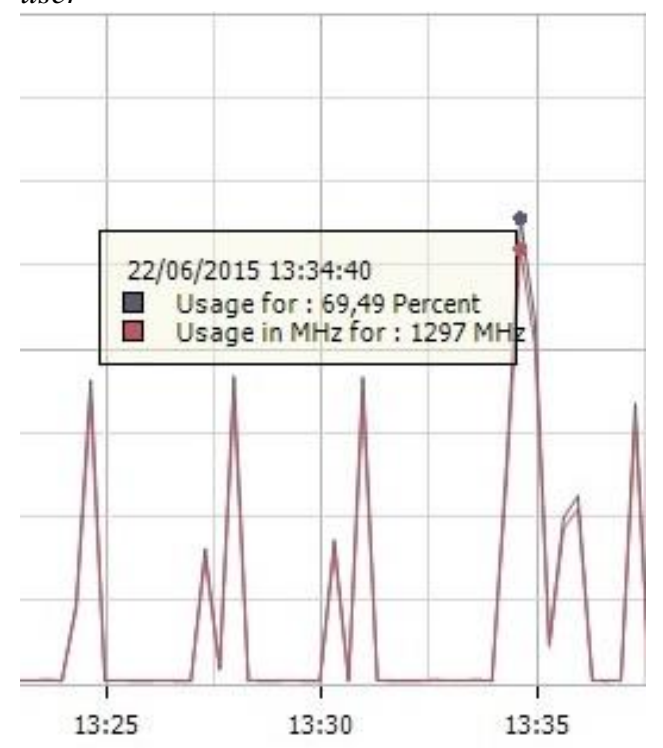

Gambar 8. Grafik CPU saat keadaan diakses 4 user

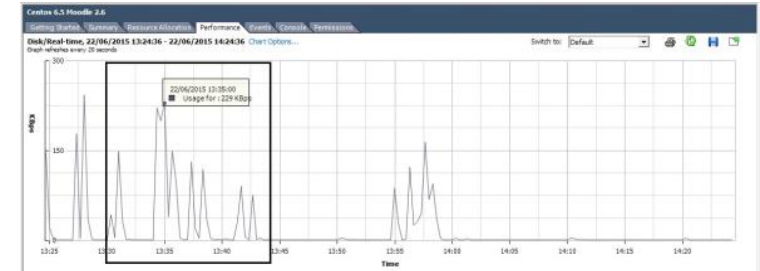

Gambar 9. Grafik Disk saat keadaan diakses 4 user

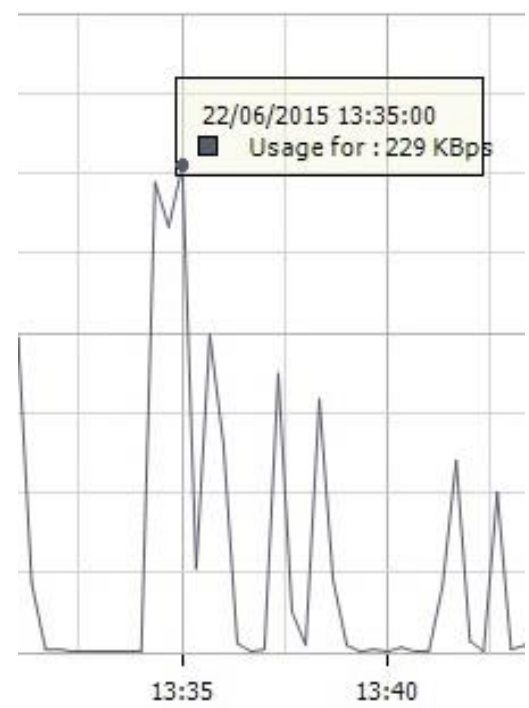

Gambar 10. Grafik Disk saat keadaan diakses 4 user

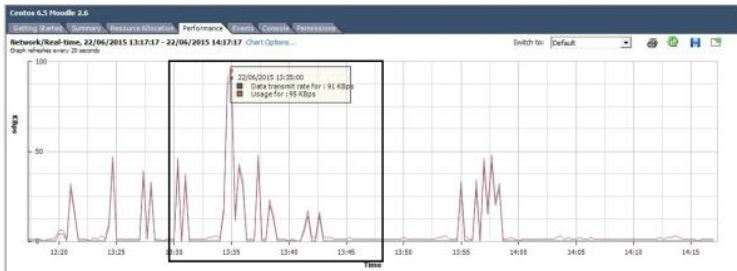

Gambar 11. Grafik Jaringan saat keadaan diakses 4 user

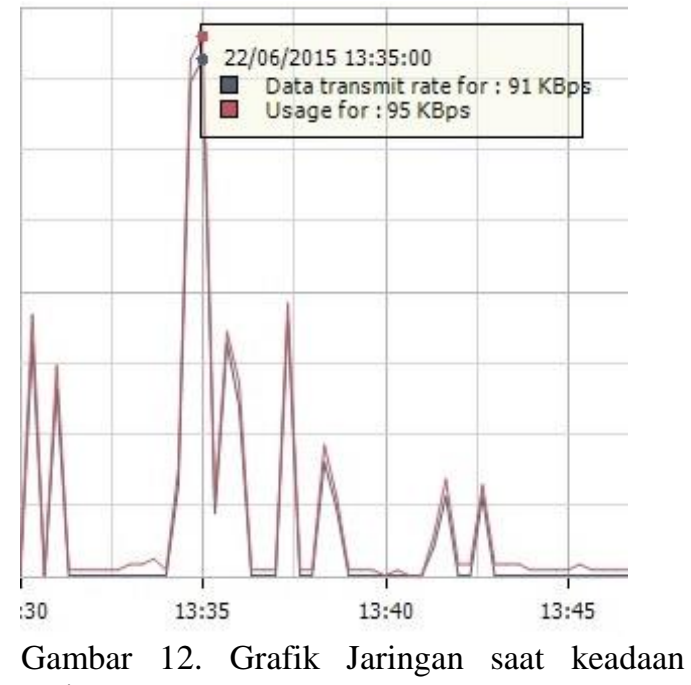
diakses 4 user

\subsection{Hasil Pengujian Skala Besar}

Pengujian skala besar dilakukan untuk mengetahui apakah perangkat server mengalami beban lebih besar kerja saat sistem E-Learning 
tersebut diakses oleh 40 user dan telah berfungsi sebagaimana mestinya atau tidak. Hasilnya adalah semua grafik kinerja telah berjalan sebagaimana mestinya tanpa ada kendala.

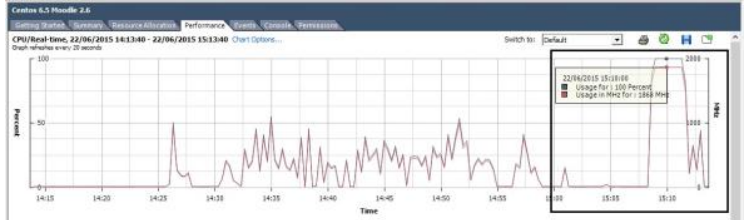

Gambar 13. Grafik CPU saat keadaan diakses 40 user

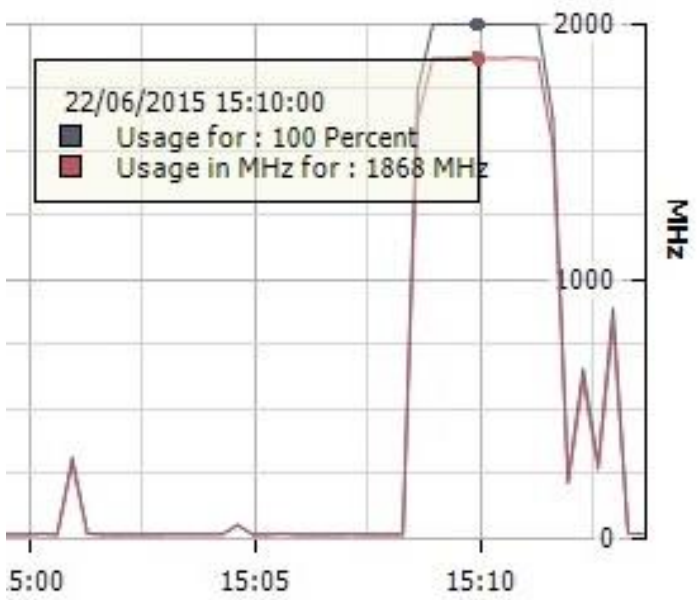

Gambar 14. Grafik CPU saat keadaan diakses 40 user

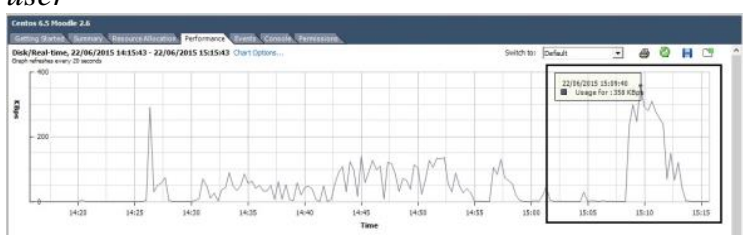

Gambar 15. Grafik Disk saat keadaan diakses 40 user

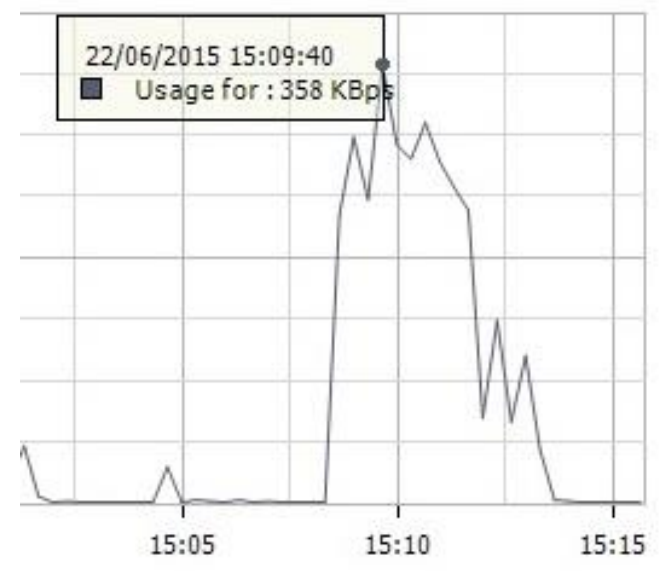

Gambar 16. Grafik Disk saat keadaan diakses 40 user

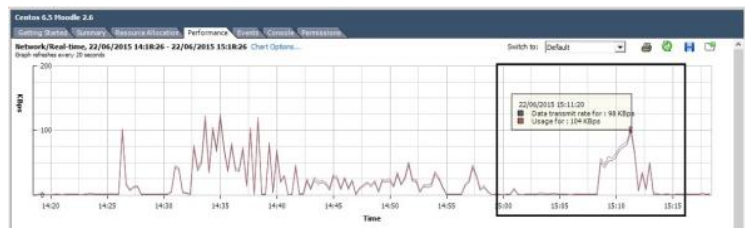

Gambar 17. Grafik Jaringan saat keadaan diakses 40 user

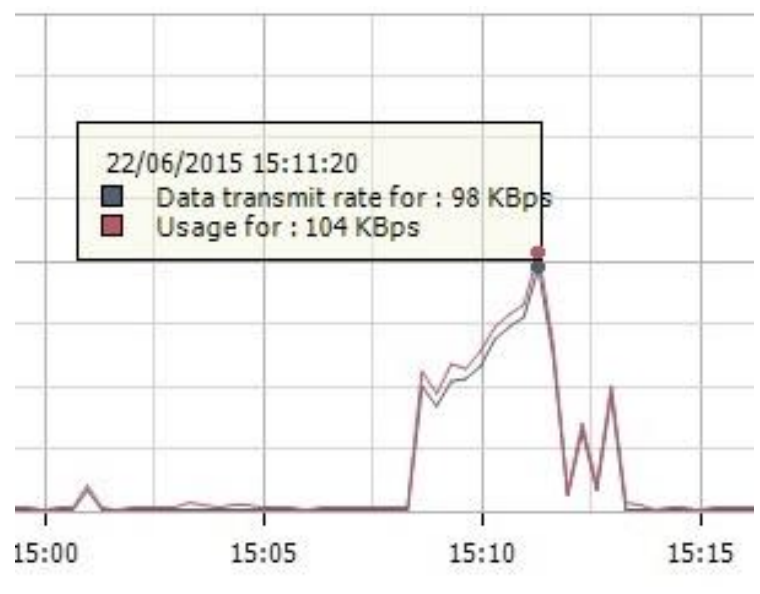

Gambar 18. Grafik Jaringan saat keadaan diakses 40 user

\subsection{Kinerja Sistem}

Dari hasil pengujian sistem E-Learning, baik dalam skala kecil maupun skala besar dapat dianalisis dan disimpulkan bahwa peningkatan/beban kinerja komponen dari server dan jaringan terjadi pada saat awal sistem E-Learning diakses oleh user, sedangkan ketika user telah berada didalam sistem dan melakukan simulasi pembelajaran dengan fitur virtual kelas maka kinerja/beban dari komponen server dan jaringan kembali stabil.

Dapat dilihat dari komponen CPU pada server walaupun terjadi lonjakan yang cukup tinggi pada saat awal diakses dalam waktu bersamaan baik pada 4 user maupun 40 user namun sistem E-Learning dapat berjalan dengan dengan baik pada saat simulasi pembelajaran. Begitu pula dengan komponen lainnya yaitu Disk dan jaringan tidak mempengaruhi kinerja pada sistem E-Learning walaupun terjadi lonjakan kinerja komponen server pada awal sistem diakses.

\subsection{Tugas Admin}

Dalam sebuah sistem E-Learning tersebut, dibutuhkan seorang admin untuk menjalankan dan memantau kinerja dari sistem yang sedang dioprasikan. Selain itu admin juga harus melakukan analisis dan identifikasi terhadap potensi masalah yang akan terjadi pada sistem E-Learning tersebut. Melakuan pemeliharaan rutin pada sistem E-Learning tersebut baik perangkat keras maupun perangkat lunak menjadi suatu kewajiban agar sistem dapat beroprasi secara optimal. Dalam perkembangannya, admin harus siap menerapkan pembaruan pada sistem dari sisi hardware maupun software sesuai kebuduhan dikemudian hari.

\section{Daftar Pustaka:}

Amiroh. 2012. Membangun e-learning dengan Learning Management System Moodle. Sidoarjo: PT Berkah Mandiri Globallindo.

Cloara, \& Jeremy, dkk.. 2008. CCNA Exam Prep, Second Edition. USA: Pearson Education, Inc.. 
Cole, J. \& Foster, H. 2008. Using Moodle 2nd Edition. San Francisco: O'Reilly Media, Inc..

Effendy, E. \& Zhuang, H. 2005. e-learning Konsep dan Aplikasi. Yogyakarta: ANDI.

Gora, W. 2005. Membuat CD Multimedia Interaktif untuk Bahan Ajar E-learning. Jakarta: Gramedia.

Horton, W. 2012. E-Learning by Design 2nd Edition. San Francisco: Jonh Wiley and Sons, Inc..

Madcoms. 2009. Membangun Sistem Jaringan Komputer. Yogyakarta: ANDI.

Prawiradilaga, S.D. dkk.. 2013. Mozaik Teknologi Pendidikan: E-Learning. Jakarta: Prenada Media.

Purwanto, E. 2010. Pengantar World Wide Web. [terhubung berkala]. http://elearning.amikom.ac.id [16 Mei 2015].

Ruest, D. 2009. Virtualization: A Beginner's Guide. San Francisco: The McGraw-Hill Companies.

Setiawan, A. 2012. Perngertian dan Jenis Server. [terhubung berkala]. http://www.transiskom.com/2012/09/pengertian -dan-jenis-server.html [24April 2015].

Sugiyono, 2013. Metode Penerapan Kuantitatif Kualitatif dan R\&D. Bandung: Alfabeta.

Tanenbaum, A.S. 1997. Jaringan Komputer. Terjemahan oleh Priatna, Gurnita; \& Indarto, Purnomo Wahyu, Jakarta: Prenhallindo.

Tim Penyusun. 2012. Buku Pedoman Skripsi/Komprehensif/Karya Inovatif. Jakarta: Univeristas Negeri Jakarta.

Vmware, Inc. 2015. vSphere Hypervisor ESXi Support Center. [terhubung berkala]. https://www.vmware.com/support/vspherehypervisor.html [7 Mei 2015].

Zulhikam, A. 2011. Fungsi dan Jenis-Jenis Komputer Server. [terhubung berkala]. http://jaringankomputer.org/server-fungsipengertian-jenis-jenis-komputer-server/ April 2015] 